\title{
KEGIATAN BELAJAR MENGAJAR BAGI ANAK PAUD DAN PENYULUHAN KESEHATAN BAGI ORANG TUA DI YAYASAN ANAK LANGIT
}

\author{
Lastiar Roselyna Sitompul ${ }^{1}$, Reisky Megawati Tammu², Wahyu Irawati ${ }^{3}$, Siane Indriani ${ }^{4}$ \\ 1,2,3,4 UniversitasPelitas Harapan \\ Email lastiar.sitompul@uph.edu, reisky.tammu@uph.edu, wahyu.irawati@uph.edu, siane.indriani@uph.edu
}

\begin{abstract}
Abstrak
Fakultas Ilmu Pendidikan UPH-Teachers College, mempunyai visi dan misi untuk mengembangkan pembelajaran transformatif dan holistis berdasarkan wawasan Kristen alkitabiah, dengan mengembangkan guruguru Kristen yang reflektif, responsif dan bertanggung jawab dan menjadi berkat untuk masyarakat. Berdasarkan visi dan misi tersebut, maka dilakukan kerjasama dengan Yayasan Anak Langit yang sangat membutuhkan pengajar untuk kegiatan belajar mengajar di yayasan tersebut. Metode yang dilakukan pada PkM ini adalah Teachers College menyediakan tutor yakni para mahasiswa mengajar anak PAUD, kegiatan penyuluhan kepada orang tua tentang pentingnya hidup sehat, pertumbuhan dan perkembangan anak, serta kiat mengatur keuangan oleh para dosen Program Studi Pendidikan Biologi. Hasil kegiatan ini menunjukkan bahwa kemampuan siswa dapat berkembang dengan baik secara kognitif, afektif, dan psikomotor, yang dituliskan dalam bentuk laporan sederhana. Adanya penerapan beberapa peraturan baru, seperti berbaris sebelum kelas dan hand signal memfasilitasi siswa dalam pengembangan karakter sejak dini. Mahasiswa sebagai tutor juga mendapat tambahan pengalaman dan mampu mengembangkan kemampuan mengajar anak-anak PAUD dalam konteks budaya Indonesia. Melalui kegiatan penyuluhan, wawasan orang tua siswa semakin bertambah dalam menjaga kesehatan keluarga, mendampingi anak-anak dalam masa pertumbuhan. Dengan demikian, kegiatan PkM ini telah memberikan dampak positif dan solusi bagi permasalahan mitra sehingga kegiatan ini akan terus dilanjutkan.
\end{abstract}

Kata kunci: Yayasan Anak Langit, Teachers College, Tutor, Penyuluhan kesehatan

\section{PENDAHULUAN}

Analisis Situasi

Sesuai dengan visi dan misi dari Fakultas

Ilmu Pendidikan Teachers College, untuk mengembangkan pembelajaran transformatif dan holistis berdasarkan Wawasan Kristen Alkitabiah, dengan menghasilkan guru-guru Kristen yang reflektif, responsif dan bertanggung jawab dengan standar internasional, yang mampu mengajar dalam konteks budaya Indonesia, sekaligus memiliki pemahaman yang transformatif dan holistis berdasarkan Wawasan Kristen Alkitabiah, maka perlu diberikan wadah kepada mahasiswa untuk mengaplikasikan pengetahuannya untuk terlibat secara langsung dalam kegiatan belajar mengajar.

$$
\text { Ekonomi, Sosial, dan Budaya }
$$


Setiap guru harus menggunakan keterampilan mereka untuk menuntun dan membimbing orangorang muda (van Brummelen, 2008). Oleh karena itu, diharapkan kegiatan bimbingan belajar ini dapat menjadi wadah bagi mahasiswa calon guru dalam belajar menjadi seorang penuntun. Peran guru Kristen untuk menuntun bukan hanya memberikan pengetahuan bagi siswa, sehingga bukan hanya menekankan dari segi kognitif. Akan tetapi, dapat menuntun siswa mempunyai afektif yang baik juga. Pada dasarnya hakikat guru adalah membantu siswa untuk mencapai keberhasilan dalam tujuan pembelajaran (Gultom et al., 2019). Kegiatan ini adalah salah satu cara mahasiswa mempraktikkan pengetahuan dan keterampilan mereka. manfaat praktik adalah agar dapat berefleksi dan memperoleh pemahaman serta pengalaman baru, sehingga meningkatkan pemahaman maupun keterampilan (Fenge et al., 2014).

Salah satu profil dari lulusan FIP Teachers College UPH adalah seorang anggota komunitas yang signifikan artinya mampu membina relasi dengan masyarakat dengan membangun komunitas yang berdasarkan anugerah, kedamaian, pengharapan dan kasih. Teachers College menjadi wadah untuk mempersiapkan para calon guru Kristen yang reflektif, responsif dan bertanggung jawab (Sitompul, 2018). Dengan demikian jelaslah bahwa selama dalam pendidikan di FIP UPH, mahasiswa harus mempunyai wadah untuk membina relasi dengan masyarakat dan melakukan tindakan kasih lewat panggilan yang sudah Allah berikan sebagai calon guru. Gambar dan rupa Allah harus mencerminkan Allah melalui tindakan mereka (Graham, 2009). Mahasiswa calon guru adalah gambar dan rupa Allah yang akan memberitakan Allah melalui pengajaran yang diberikan selama kegiatan bimbingan belajar. Guru Kristen tidak hanya dipandang sebagai pekerjaan semata, melainkan sebuah panggilan Allah, dan Allah sendiri yang memampukan setiap guru atas panggilan yang dikerjakan.

Anak Langit adalah sebuah komunitas yang berfokus kepada kegiatan pemberdayaan anak-anak terutama yang memiliki kehidupan sosial ekonomi di bawah rata-rata. Semua siswa memiliki kesempatan untuk belajar dan tumbuh dalam komunitas belajar bersama dengan teman sebayanya (Katz, 2012). Belajar merupakan suatu proses yang dilakukan untuk memperoleh pemahaman baru yang menghasilkan perubahan sifat dan Tindakan yang lebih baik. Secara formal, komunitas ini berbentuk Yayasan Anak Langit (Semanggi) yang memiliki visi untuk menyelenggarakan kegiatan sosial dan kemanusiaan berfokus pada anak-anak yang berlandaskan prinsip non-partisan, jujur, independen, mandiri, dan profesional, serta menjunjung tinggi etika dan semangat kebersamaan. Teachers College yang bergerak di bidang pendidikan dapat menjadi mitra yang tepat untuk melakukan kegiatan pendidikan di Yayasan Anak Langit dengan memberikan layanan pendidikan bagi anak usia dini, usia sekolah dan rindu untuk sekolah tanpa dipungut biaya apapun. Seperti diketahui bahwa pendidikan tidak hanya sebatas pada sebuah sekolah (Zendrato et al., 2019). Hal ini berarti bahwa pendidikan juga dapat diperoleh dari melalui bimbingan belajar. Melalui bimbingan belajar siswa dibantu dalam mengembangkan diri, sikap, dan kebiasaan belajar agar dapat menguasai pengetahuan dan keterampilan (Susanto, 2018). Bimbingan belajar juga dapat membantu murid memecahkan kesulitan maupun permasalahan yang berkaitan dengan masalah belajar sehingga tujuan belajar dapat tercapai.

Permasalahan Mitra

Yayasan Keluarga Anak Langit ini dimulai sejak tahun 2004, dan telah membantu banyak anak usia sekolah yang terancam tidak bersekolah, hal ini disebabkan faktor ekonomi. Kondisi di lapangan menunjukkan bahwa sangat sulit bagi Yayasan Anak Langit untuk mendapatkan tenaga pendidik yang benar-benar mempunyai latar belakang pendidikan guru dan hadir secara reguler. Melalui kerjasama dengan FIP UPH akan sangat menolong yayasan ini untuk tetap memberikan pendidikan bagi anak-anak PAUD yang orang tuanya tidak sanggup memasukkan mereka ke sekolah resmi. Oleh karena itu, Yayasan Anak Langit (Semanggi) sangat mengharapkan adanya kerjasama dengan pihak FIP UPH yang akan terus berlanjut hal ini bertujuan untuk mendukung dan memfasilitasi kegiatan pembelajaran yang dilakukan di rumah belajar Anak 
Langit dengan menyediakan tutor untuk kegiatan belajar mengajar.

Solusi

Untuk mengatasi kesulitan yang dihadapi oleh mitra, maka FIP Teachers College UPH menyediakan tutor yaitu mahasiswa yang akan mengajar anak-anak PAUD sesuai jadwal setiap hari Senin sampai Sabtu secara bergantian. Teachers College juga memfasilitasi biaya transport yang dibutuhkan oleh mahasiswa ke tempat Yayasan Anak Langit. Di lain pihak, kegiatan pembelajaran tersebut juga membantu mahasiswa FIP UPH mengaplikasikan pengetahuannya, mampu mengajar dalam konteks budaya Indonesia, dan berelasi dengan masyarakat sekitar. Dosen-dosen ikut berpartisipasi membimbing dan mendukung kegiatan pembelajaran di Yayasan Anak Langit dengan memberikan penyuluhan kepada kaum ibu yang meliputi pentingnya hidup sehat, pertumbuhan dan perkembangan anak, kiat-kiat mengatur keuangan rumah tangga. Oleh sebab itu, tujuan dari bimbingan belajar Anak Langit yaitu: 1) Memberikan pengajaran bagi anak usia dini baik untuk jenjang Kelompok bermain, TK A, dan TK B; 2) Menjadi berkat untuk setiap anak yang tergabung di Yayasan Anak Langit dan berkomitmen untuk mengajar mereka dengan sepenuh hati, 3) Mengajarkan konten dan karakter yang baik, dan secara implisit memperkenalkan Kristus kepada mereka melalui teladan hidup para tutor, 4) Mengasah talenta yang dimiliki oleh setiap anak dengan melatih hal-hal yang digemari anak yang bersifat mendidik; 5) Menjadi ajang dalam melatih kemampuan mengajar bagi setiap para tutor; 6) Berbagi informasi dan pengalaman kepada kaum ibu mengenai pentingnya hidup sehat, pertumbuhan dan perkembangan anak, serta kiat-kiat mengatur keuangan rumah tangga.

\section{Luaran}

Target luaran dari kegiatan pengabdian kepada masyarakat ini adalah: 1) Melalui kegiatan belajar mengajar yang dilakukan di Yayasan Anak Langit, anak-anak siap untuk melanjutkan pendidikan ke tingkat SD; 2) Mahasiswa FIP-TC UPH sebagai tutor mendapat tambahan pengalaman dan mampu mengembangkan kemampuan mengajar anak-anak PAUD dalam konteks budaya Indonesia;
3) Kerja sama antara FIP-TC UPH dengan Yayasan Anak Langit dapat terus terjalin dengan baik.

\section{METODE}

Pelaksanaan kegiatan pengabdian kepada masyarakat dilakukan dalam dua bentuk yaitu: a) Kegiatan Belajar Mengajar (KBM) yang melibatkan 5 orang mahasiswa sebagai tutor untuk mengajar anak-anak PAUD di Yayasan Anak Langit setiap hari Senin sampai dengan Sabtu mulai pukul 08.30 11.15 WIB. Lokasi pelaksanaan KBM yaitu rumah belajar Yayasan Anak Langit di Jalan Perintis Kemerdekaan II Nomor 4, Cikokol, Tangerang. Waktu tempuh dari UPH ke lokasi pelaksaan KBM adalah sekitar 30-45 menit. Konsep pembelajaran yang dilakukan adalah "Sekolah Alam" yang berfokus pada pemberian materi terkait: moral dan nilai-nilai agama, fisik, karakter, bahasa, kognitif, sosial dan emosi, seni, dan pengenalan lingkungan hidup.

Kegiatan belajar mengajar ini akan selalu dievaluasi sekali dalam sebulan. Evaluasi adalah menilai kesenjangan antara standart yang di tetapkan dengan yang terjadi di lapangan (Zahroh, 2015). Menurut Kadek (2017) evaluasi dapat menentukan tingkat penguasaan siswa terhadap tujuan pembelajaran. Hal ini ini membuktikan bahwa evaluasi sangat penting dilakukan karena dapat melihat peningkatan hasil kerja, memperbaiki, dan dapat meningkatnya menjadi lebih baik. PIC mahasiswa di lapangan menyampaikan laporan kegiatan dan penggunaan dana transportasi dalam setiap 1 bulan. Jika ada mahasiswa yang tidak berkomitmen menjalankan tanggung jawabnya sebagai tutor, maka akan ditinjau ulang keterlibatannya dalam program ini. PIC mahasiswa juga bertugas menyediakan daftar hadir tutor; b) Kegiatan penyuluhan kepada para orang tua siswa khususnya kaum ibu oleh 5 dosen Program Studi Pendidikan Biologi tentang: 1) Pentingnya hidup sehat; 2) Pertumbuhan dan perkembangan anak; 3) Kiat-kiat mengatur keuangan rumah tangga.

\section{HASIL DAN PEMBAHASAN}

\section{Pelaksanaan}

Sebelum Kegiatan Belajar Mengajar (KBM) mulai dilakukan, hal yang paling utama dilakukan para tutor berkumpul membuat perencanaan

$$
\text { Ekonomi, Sosial, dan Budaya }
$$


pembelajaran yang merupakan pembawa keberhasilan dalan proses pembelajaran dan menghias kelas juga suatu yang penting karena sangat mempengaruhi siapapun yang ada di dalam kelas seperti membangkitkan semangat bagi siswa pada 2 September 2017 (Gambar 1). Kegiatan persiapan tersebut melibatkan semua tutor yaitu para mahasiswa FIP UPH dan dibantu juga oleh pihak Yayasan Anak Langit (Semanggi) agar proses dapat berjalan dengan efektif.

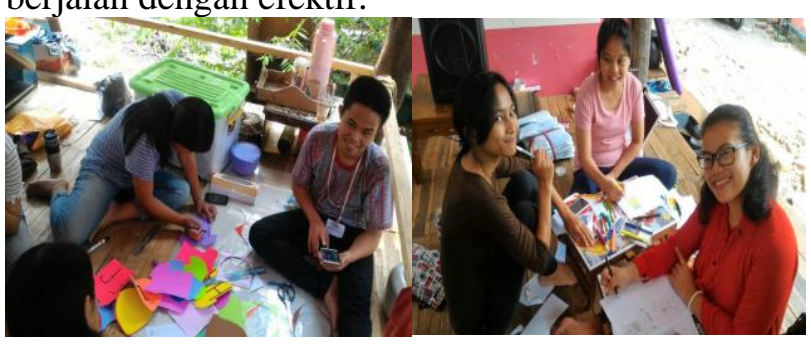

Gambar 1. Persiapan para tutor sebelum pelaksaan KBM

KBM mulai diselenggarakan pada Rabu, 6 September 2017. Jadwal tetap untuk pelaksanaan KBM yaitu Rabu sampai dengan Jumat mulai pukul $08.00-10.15$ WIB. Hal ini berbeda dengan perencanaan sebelumnya karena ditemukan kendala yaitu kesulitan dalam mendapatkan tutor yang memiliki waktu kosong pada hari Senin dan Selasa pagi. Selain itu, di Universitas Pelita Harapan juga diadakan kegiatan ibadah yang diwajibkan untuk diikuti oleh mahasiswa FIP pada Selasa pagi.

Jadwal keberangkatan tutor dari Universtas Pelita Harapan adalah pukul 07.00 WIB dengan menggunakan Grabcar. Pada umumnya tutor sampai di lokasi KBM yaitu Rumah Belajar Yayasan Anak Langit di Jalan Perintis Kemerdekaan II Nomor 4, Cikokol, Tangerang sekitar pukul 07.30-07.45 WIB. Selama pelaksanaan kegiatan PkM tidak ditemukan atau dilaporkan adanya kendala atau masalah terkait dengan transportasi yang digunakan. Konsep pembelajaran yang dilakukan bagi anak-anak usia TK berfokus pada pendidikan moral dan nilai-nilai agama, fisik, karakter, bahasa, kognitif, sosial dan emosi, seni dan pengenalan lingkungan hidup (Gambar 2).

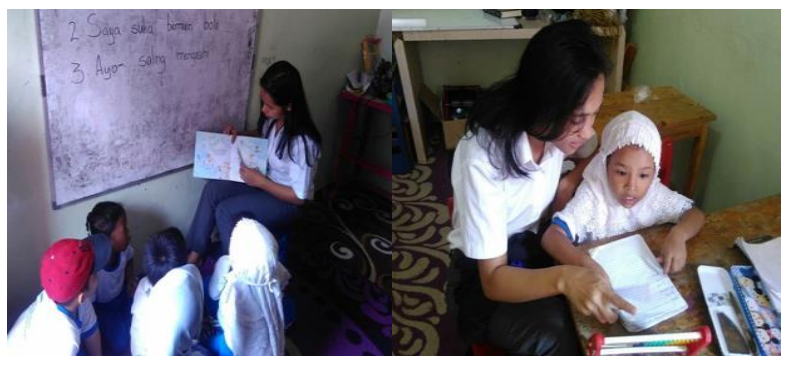

Gambar 2. Pelaksanaan KBM di Yayasan Anak Langit (Semanggi)

Dalam pelaksanaan KBM ditemukan beberapa kendala serta solusi yang telah diberikan, diantaranya: 1) Kondisi tempat belajar, lokasi ruangan tempat mengajar di Anak Langit masih kurang tertata dengan baik. Lingkungan juga kurang bersih dan kondisi kelas kurang nyaman karena udara yang masuk ke dalam kelas. Untuk mengatasi hal tersebut, para tutor meluangkan waktu untuk membersihkan ruang belajar terlebih dahulu sebelum mengajar. Kenyamanan ruang kelas hal yang penting dikarenakan tercapainya situasi yang kondusif dan meningkatkan produktivitas proses pembelajaran (Wahyudi \& Azizah, 2016). Pengolahan kelas adalah salah satu cara dalam menciptakan lingkungan kelas yang kondusif. Situasi kondisi ini juga sangat mempengaruhi rasa nyaman dan kesiapan siswa untuk belajar; 2) Materi pembelajaran yang disampaikan dari hari ke hari oleh para tutor masih kurang terstruktur. Hal ini terjadi karena kegiatan pembelajaran dalam PkM ini masih dalam tahap transisi dari model bimbingan belajar konvensional menjadi bimbingan belajar yang mengadopsi sistem sekolah formal. Sejauh ini telah dilakukan studi pustaka dan diskusi untuk menentukan perangkat kurikulum yang digunakan untuk anak-anak PAUD/TK. Untuk ke depannya, akan dilakukan penyusunan perangkat kurikulum untuk TK Semanggi secara lebih sistematis agar terdapat panduan yang tetap dan jelas serta sesuai dengan kondisi para siswa. Hal ini dikarenakan, materi pembelajaran merupakan salah satu aspek yang dapat mempengaruhi output, yang berarti kualitas proses dan hasil pembelajaran sangat berpengaruh oleh materi pembelajaran yang digunakan (Sorraya, 2014); 3) Kreativitas dan kehadiran, para tutor masih 
perlu lebih kreatif menyusun rencana pembelajaran dengan bahan ajar yang tersedia. Dalam mengajar bukan hanya sekedar menyampaikan ilmu pengetahuan, melainkan dapat menciptakan sistem lingkungan yang membelajarkan peserta didik agar tujuan pembelajaran dapat tercapai secara optimal (Pentury, 2017). Pengajar pelu mengembangkan kreativitas dalam mengelola program pembelajaran dengan strategi belajar mengajar dengan berbagai variasi. Kreativitas pembelajaran tidak terpisah dengan proses belajar mengajar (Lusiana et al., 2015). Pengajar pelu mengembangkan kreativitas dalam mengelola program pembelajaran dengan strategi belajar mengajar dengan berbagai variasi. Selain itu, kesulitan juga dialami ketika ada tutor yang harus make-up kelas atau mengikuti UTS/UAS yang bertepatan dengan jam mengajar. Oleh sebab itu, hal yang dilakukan adalah PIC berupaya menggantikan ataupun mencari tutor sementara; 4) Kondisi para tutee, sebagian anak (tutee) sulit untuk berpisah dengan orangtuanya ketika akan belajar (Anak TK A). Selain itu, beberapa anak kadang tidak dapat hadir karena bertempat tinggal jauh dari rumah belajar Anak Langit ataupun ada yang tidak dapat diantar dan didampingi oleh orangtua mereka. Sejauh ini hanya dilakukan diskusi dengan para orangtua dan mendorong mereka untuk dapat mengusahakan agar dapat mengantar anak-anaknya belajar; 5) Orang tua, ada beberapa orangtua yang masih belum sepenuhnya dapat meninggalkan para tutee ketika sedang belajar. Hal yang dilakukan adalah memberikan pengertian kepada orang tua agar dapat mendorong anaknya untuk lebih mandiri selama belajar. Selain itu, orang tua juga belum terlalu paham mengenai masalah kesehatan dan gizi anak-anak mereka sehingga hampir semua sarapan dan jajan anak-anak berupa mie instan dan snack yang kurang sehat. Seorang anak membutuhkan makanan yang mengandung nutrisi untuk meningkatkan konsentrasi dan kemampuan belajar (Perretta, 2017). Oleh sebab itu, dilakukan kegiatan penyuluhan pentingnya hidup sehat dikaitkan dengan pertumbuhan dan perkembangan anak bagi para orang tua oleh dosen-dosen Prodi Pendidikan Biologi.

Kegiatan penyuluhan kepada para orang tua siswa khususnya kaum ibu dilakukan oleh 3 orang dosen dari Program Studi Pendidikan Biologi,
Fakultas Ilmu Pendidikan UPH. Kegiatan penyuluhan (Gambar 3) diikuti oleh sekitar 15 orang tua murid (ibu) dalam waktu selama kurang lebih 90 menit dengan agenda penyampaian materi 60 menit dan tanya jawab selama 30 menit. Adapun materi yang disampaikan dalam pertemuan orang tua ini adalah tentang pentingnya hidup sehat, dan pertumbuhan dan perkembangan anak. Namun untuk topik penyuluhan mengenai kiat-kiat mengatur rumah tangga belum disampaikan hal ini dikarenakan waktu yang terbatas serta lebih diprioritaskan untuk membahas masalah kesehatan dan pertumbuhan anak. Pada kegiatan tersebut, bukan hanya disediakan konsumsi bagi kaum ibu namun anak-anak juga dibagikan snack berupa roti dan susu. Kegiatan penyuluhan orangtua dilakukan pada saat yang bersamaan dengan waktu belajar para tutee, sehingga orang tua juga dapat melihat juga proses pembelajaran dan interaksi tutor maupun tutee. Melalui bimbingan belajar ini dapat dilihat juga bahwa bukan hanya siswa yang mendapatkan pengetahuan maupun pemahaman yang baru, tetapi orang tua juga.

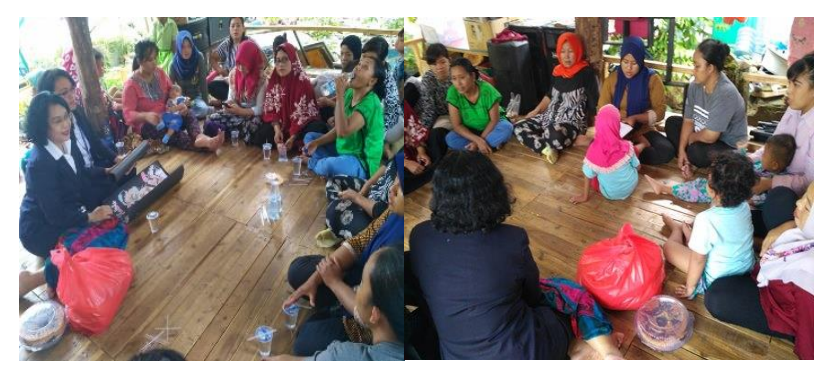

Gambar 3. Pelaksanaan kegiatan penyuluhan oleh para dosen FIP UPH kepada kaum ibu di Yayasan Anak Langit (Semanggi)

\section{Hasil Kegiatan}

Kegiatan PkM yang telah dilakukan baik berupa bimbingan belajar maupun penyuluhan kepada orangtua telah memberikan hasil sebagai berikut: 1) Melalui kegiatan belajar mengajar, tujuan bimbingan belajar tercapai hal ini dapat dilihat dari kemampuan siswa dapat berkembang dengan baik secara kognitif, afektif, dan psikomotor. Hal ini dapat dilihat dari hasil belajar siswa yang dituliskan

$$
\text { Ekonomi, Sosial, dan Budaya }
$$


dalam bentuk rapor yang sederhana. Melalui rapor trsebut para tutor memberitahukan mengenai perkembangan setiap siswa kepada orangtua di akhir kegiatan PkM melalui pembagian laporan perkembangan siswa atau rapor (Gambar 4).

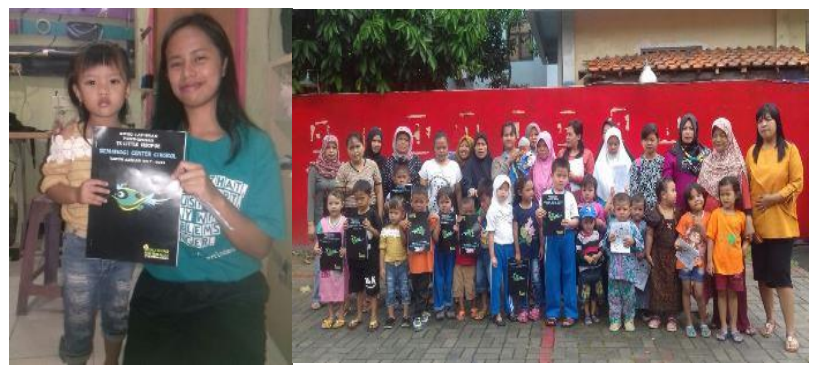

Gambar 4. Pembagian laporan perkembangan siswa pada akhir kegiatan PkM di Yayasan Anak Langit (Semanggi)

2) Adanya penerapan beberapa peraturan baru, seperti berbaris sebelum kelas dan hand signal memfasilitasi siswa dalam pengembangan karakter sejak dini. Hal ini merupakan penerpan yang baik diusia dini agar siswa sudah mulai bisa mengikuti aturan yang diberikan dengan baik; 3) Mahasiswa TC sebagai tutor juga mendapatkan pengetahuan maupun pengalaman tambahan dan mampu mengembangkan kemampuan mengajar anak-anak PAUD dalam konteks budaya Indonesia; 4) Melalui kegiatan penyuluhan ini bukan hanya tutor maupun siswa yang mendapatkan wawasan, orang tua siswa juga semakin mendapatkan wawasan untuk menjaga kesehatan keluarga dan mendampingi anak-anak dalam masa pertumbuhan dengan lebih baik lagi; 5) Kegiatan PkM ini juga semakin mempererat kerja sama antara Universitas Pelita Harapan Fakultas Ilmu Pendidikan dengan Yayasan Anak Langit (Semanggi).

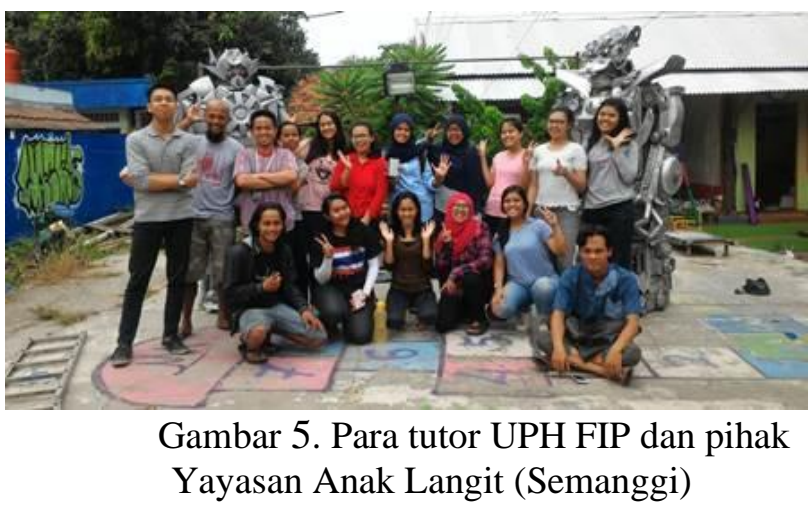

\section{KESIMPULAN}

Kegiatan PkM term 1 ini sudah berjalan dengan baik walaupun tidak dapat dipungkiri bahwa ada beberapa kendala terkait pelaksanaan proses pembelajaran di lapangan. Melalui evalusi kami berharap kegiatan PkM term 1 ini dapat lebih baik kerdepannya. Kami juga berharap kegiatan ini terus berlanjut dan semakin efektif pada semester berikutnya untuk memberikan pendidikan yang terbaik kepada para siswa di Yayasan Bimbingan Anak Langit. Kiranya kegiatan ini memberikan manfaat yang baik bagi kita semua dan paling utama membawa kemuliaan bagi nama Allah.

\section{REFERENSI}

Astiti, K. A. (2017). Evaluasi Pembelajaran. Yogyakarta:Andi Offset.

Fenge, L.-A., Howe, K., Hughes, M., \& Thomas, G. C. (2014). The Social Work Portfolio: A Student's Guide to Evidencing Your Practice. Berkshire: Open University Press.

Graham, D. (2009). Teaching Redemptively. Colorado Springs: Purposeful Design Publications.

Gultom, E. L., Sitompul, H., \& Tamba, K. T. (2019). Guru Kristen sebagai Penuntun Belajar Siswa Kelas XII di Satu Sekolah Kristen. Jurnal of Holistic Mathematics Education, 65.

Katz, J. (2012). Teaching to Diversity: The Three-Block Model of Universal Design for Learning. Winnipeg: Portage \& Main Press. 
Lusiana, Matsum, J. H., \& Ulfah, M. (2015). Analisis Kreativitas Guru dalam Proses Belajar Mengajar pada Mata Pelajaran Ekonomi Kelas XI SMA. Jurnal Administrasi Pendidikan, 3.

Pentury, H. J. (2017). Pengembangan Kreativitas Guru Dalam Pembelajaran Kreatif. Faktor Jurnal Ilmiah Kependidikan, 4 (3): 266-267.

Perretta, L. (2017). Makanan untuk Otak: Panduan Penting untuk Meningkatkan Kemampuan Otak. Jakarta: Esensi

Sitompul, L. R. (2018). Kompetensi Pedagogik Mahasiswa Program Studi Pendidikan Biologi UPH-Teachers Collage Pada PPL-3. Jurnal Seminar Nasional Edusaintek, 88.

Sorraya, A. (2014). Pengembangan Bahan Ajar Teks Prosedur Kompleks Dalam Pembelajaran Bahasa Indonesia. Jurnal NOSI, 2 (2): 14-16.
Susanto, A. (2018). Bimbingan dan Konseling di Sekolah. Jakarta: Prenadamedia Group. Wahyudi, D., \& Azizah, H. (2016). Strategi Pembelajaran Menyenangkan Dengan Konsep Learning Revolution. Jurnal Attarbiyah, 26: 4-7.

Zahroh, M. N. (2015). Evaluasi Kinerja Guru Dalam Peningkatan Mutu Pendidikan. Jurnal Manajemen Pendidikan, 140-141.

Zendrato, J., Putra, J. S., Cendana, W., Susanti, A. E., \& Munthe, A. P. (2019). Kurikulum Bagi Pemula. Surakarta: Oase Group.

Van Brummelen, H. V. (2008). Batu Loncatan Kurikulum. Jakarta: Universitas Pelita Harapan Press. 